\title{
Effect of Helicobacter pylori Infection on Insulin Resistance in non-Obese, non-Diabetic Patients
}

\author{
Ashraf A. Askar', Ahmed A. M. Abdallah' ${ }^{2}$, Ahmed Sedky ${ }^{3}$, \\ El-Zahraa M. Meghezel ${ }^{4}$, and Ali H. Mohammed ${ }^{1}$ \\ ${ }^{1}$ Department of Internal Medicine, Faculty of Medicine, Sohag University, Sohag, \\ Egypt . \\ ${ }^{2}$ Department of Medical Biochemistry, Faculty of Medicine, Sohag University, Sohag, \\ Egypt . \\ ${ }^{3}$ Department of Clinical Pathology, Faculty of Medicine, Sohag University, Sohag, \\ Egypt . \\ ${ }^{4}$ Department of Tropical Medicine and Gastroenterology, Faculty of Medicine, Sohag \\ University, Sohag, Egypt .
}

Corresponding Author Ashraf A. Askar

Mobile: +201002426002

E mail: ashrafaskar15@gmail. com

Key words: Helicobacter pylori; Insulin resistance; HOMA-IR.
Background and study aim: Helicobacter pylori is associated with the inflammation of the mucosa-associated lymphoid tissues throughout the digestive tract. Infection by $H$. pylori is related to insulin resistance (IR). The Homeostatic model assessment of IR (HOMA-IR) is a reliable method for assessing IR by basal glucose and insulin levels in humans. The current approach aimed to use the HOMA-IR index to study the relation between $H$. pylori and IR in non-obese and non-diabetic patients.

Patients/Materials and Methods: 62 participants were divided into $H$. pyloripositive and control groups. All participants were non-obese, non-diabetic, and registered in the outpatient virology clinics, Department of Gastroenterology and Hepatology, Sohag University Hospital, Egypt. We performed different laboratory investigations such as liver functions, fasting blood sugar, and fasting blood insulin. HOMA-IR was calculated

\section{INTRODUCTION}

Helicobacter pylori (H. Pylori) is one of the Gram-negative bacteria, which was previously known as Campylobacter pylori, a spiral macrophile which attacks and lives in the human stomach [1]. H. Pylori was first identified in 1982 by Barry Marshall and Robin Warren as the cause of active chronic gastritis in the gastric epithelium [2]. H. Pylori is associated with the inflammation of the mucosa-associated lymphoid tissues through the digestive tract [3], which might participate in the for each participant of the study population .

Results: H. pylori infections were most common among male (73.5\%) compared to females $(26.5 \%)$ patients with a significant $\mathrm{P}=0.003$. $H$. pylori infections were associated with higher levels of $\mathrm{C}$ reactive protein $(\mathrm{CRP}), \mathrm{P}=0.039$. The levels of serum fasting insulin were higher in $H$. pylori-positive patients $(16.95 \pm 4.67 \mu \mathrm{U} / \mathrm{ml})$ than the uninfected individuals $(10.49 \pm 6.5 \mu \mathrm{U} / \mathrm{ml}), \mathrm{P}=0.001$. The values of the HOMA-IR index were significantly higher $(3.8 \pm 1.16)$ with $\mathrm{H}$. pylori infection, as well, $\mathrm{P}=0.001$.

Conclusion: HOMA-IR index is a reliable indicator of IR in $H$. pyloriinfected patients from Sohag, Egypt. Further longitudinal cohort studies are required to investigate the usage of HOMA-IR to predict $H$. pylori-associated diseases in different medical centers from Egypt.

prognosis of other serious diseases such as gastric cancer [4]. H. Pylori infection is usually asymptomatic, however in severe infection, it might cause gastritis or ulcers in the stomach or even in the duodenum [3]. Sometimes, it can cause an inflammation of the lymphoid tissue surrounding the eye, called ocular adnexal Mucosa-Associated Lymphoid Tissue (MALT) lymphoma [5]. Furthermore, the infection by $H$. pylori might cause sharp deficiencies in the levels of some vitamins (A, C, $\mathrm{E}$, and $\mathrm{B} 12$ ) and minerals (Iron and 
Copper), which is a dangerous risk factor in some medical situations such as pregnancy and breastfeeding [6]. H. pylori affect the melatonin secretion and functions, which further disturb the sleep-wake cycles, as well [5].

The infection by $H$. pylori is related negatively to the serum levels of leptin and positively to the tumor necrosis factor $\alpha \quad(\mathrm{TNF}-\alpha)$, which commonly induces insulin resistance (IR) and the development of metabolic syndrome (MS) [7-9]. IR is a pathologic condition in which the normal insulin levels are not sufficient to function perfectly in the peripheral tissues to allow glycogen storage [10]. In humans, IR was found not to be associated with impaired insulinstimulated glucose disposal [11], but with atherosclerosis and other cardiovascular diseases, as well [12]. The prognosis of IR is commonly associated with the excessive production of inflammatory cytokines such as (IL-8, IL-10, IL12) and acute-phase proteins such as CRP [13]. The prevalence of IR increased all over the past years (15.5 to $46.5 \%$, among adults) with associated metabolic disorders, particularly with older ages [14]. IR was found to be affected with different variations in the hormones that regulate insulin metabolism, such as gastrointestinal hormone, which deficiency is a common symptom of $H$. pylori infection, as well [15].

The Homeostatic model assessment (HOMA) is a reliable algorithm to evaluate the $\beta$-cell function and IR by basal (fasting) glucose and insulin levels in humans [16]. It was defined and developed in 1985 by Matthews and colleagues from the Diabetes Research Laboratories, Radcliffe Infirmary, Oxford, UK [16]. The combinational term (HOMA-IR) was used to describe a simple and convenient method to evaluate the level of IR and its correlation to the clamp-measured total glucose disposal [17-18].

To our knowledge, there is a limited number of reports related to the usage of the HOMA-IR model to study the relationship between $H$. pylori infection and the abnormal IR, however, there few studies were conducted in Egypt. So, the current study aimed to evaluate the effect of $H$. pylori on insulin resistance in non-obese and non-diabetic patients, registered in the outpatient virology clinics, Department of Gastroenterology and Hepatology, Sohag University Hospital, Egypt, using the HOMA-IR model.

\section{PATIENTS AND METHODS}

This study was conducted in outpatient clinic of Sohag University Hospital, Sohag, Egypt, in the period between February 2019 and December 2020. 62 patients were recruited in the study where all of them were complaining of various gastrointestinal manifestations and fulfilling the inclusion and exclusion criteria. Patients older than 30 years with various gastrointestinal symptoms with positive test for $H$. pylori infection (positive $H$. pylori stool Antigen test) were included. On the other hand, patients with liver cirrhosis, chronic renal failure (with or without dialysis), polycystic ovary, obese (BMI $\geq 30 \mathrm{~kg} / \mathrm{m} 2$ ), treated with non-steroidal antiinflammatory drugs (NSAIDS), and smokers were excluded from the current study. Besides, patients with local or systemic infection, diabetic, hypertensive, or those received eradication therapy for $H$. pylori in the last four weeks were excluded, as well. Patients were divided into two groups according to the positivity of $H$. pylori test; control group (1) with $H$. pylori negative and group (2) were $H$. pylori positive by stool antigen test for $H$. pylori infection. HOMA-IR index was used to assess insulin resistance.

All patients and controls were equally tested to the following variables: full medical history report, complete clinical examination, and routine laboratory investigations including complete blood count, serum total cholesterol, high-density lipoprotein, low-density lipoprotein, and triglycerides, liver and kidney functions tests, CRP by latex agglutination, fasting blood glucose, and fasting insulin levels. BMI was calculated as body weight $(\mathrm{kg}) /$ height $^{2}(\mathrm{~m})$.

\section{Laboratory investigations:}

To assess the $H$. pylori infection, a fresh stool sample is collected in sterile container and used for assessment of $H$. pylori Antigen. $H$. pylori infection was detected serologically by using the commercially available enzyme-linked immunesorbent assay (ELISA) kits ( $H$. pylori IgG ELISA kit, Padtan Elm Co., Tahran, Iran) and (H. pylori Qualitative ELISA kit; Eagle Biosciences Inc., Amherst, NH, USA) following the manufacturer guidelines.

To investigate the above-mentioned laboratory examinations; an amount of $5 \mathrm{ml}$ of venous blood was withdrawn from each participant, under aseptic conditions. The blood samples were 
allowed to clot at room temperature for 30 minutes and then were centrifuged at 2000-3000 rpm for 15 minutes. The sera supernatants were collected and divided into three aliquots:

a) The portion was used for measurement of fasting blood glucose level (Pars Azmoon commercial kit, Pars Azmoon, Tehran, Iran), ALT (alanine aminotransferase), AST (aspartate aminotransferase), blood urea, and sCr) (serum creatinine) levels. A dedicated spectrophotometer (Cobas C 311 Chemistry Analyser System, Roch Diagnostic GmbH, Indianapolis, IN, USA) was used for OD measurements.

b) The second portion was used to measure the levels of fasting serum insulin level by using by a suitable Immunenzymometric assay (IEMA) (ST AIA-PACK IRI, Tosoh Bioscience Inc., South San Francisco, CA, USA) and a dedicated ELIZA plate reader (ARCHITECT i1000SR immunoassay analyzer, Abbott Laboratories, Chicago, IL, USA).

c) The third portion was used for the assessment of CRP by using Synchron Lx 20 Autoanalyser (Beckman Coulter, Fullertron, CA, USA).

To calculate the HOMA-IR, we used the following equation as described before [18]:

$$
\begin{aligned}
\text { Fasting glycemia }\left(\frac{m g}{d l}\right) \times \\
\text { HOMA - IR }=\frac{\text { Fasting insulinemia }\left(\frac{\mu U}{m l}\right)}{405}
\end{aligned}
$$

\section{Statistical analysis:}

The results and data from the above-mentioned observations and tests were analysed by the Statistical Package for Social Science (SPSS) (SPSS version 25, IBM, Armonk, NY, USA). Pearson Chi-Square was used to assess the significance of different variables between the two groups. The correlations between homeostasis model assessment of insulin resistance and other variables of the study were assessed by Pearson product-moment correlation coefficient (PPMCC) to calculate the Pearson's r values and detect the significance of variables at $P$ value $<0.05$.

\section{RESULTS:}

In the current study, the participants were divided into two groups according to the results of stool antigen tests for $H$. pylori infection. As shown in Table 1, 35 males versus 27 females were recruited in the study. The results of stool antigen test showed that $H$. pylori infections were most common among male patients $(73.5 \%$ of positive cases) compared to females (26.5\%) with a significant $P=0.003$. All participants had an overall BMI of $26.59 \pm 1.48 \%$, which indicated that most of the participants had normal or little higher weights, but were definitely, not obese. However, the results indicated that patients with $H$. pylori infection had significant increases in BMI values, but were still not obese, $P=0.001$. All participants had an overall mean age of $47.24 \pm 5.43$ years without any significant variation among patients and control groups.

The laboratory investigations showed significant variation in the results of CRP levels between patients and control groups, $P=0.039$. Despite the results of the other blood tests didn't show any significance, the levels of AST, Urea, and $s C r$ were slightly higher in $\mathrm{H}$. pylori-infected patients, compared to the control group. By contrast, the levels of ALT were lower in $H$. pylori-infected group, despite insignificancy, as well. Most of the participants (81\%) had different types of symptoms, despite none of them were significant to $H$. pylori infection (Table 1).

As shown in Table 2, all participants had normal fasting blood glucose level, as they are nondiabetic, however no significant difference were found between $H$. pylori-infected and noninfected individuals. On the contrary, the serum levels of fasting Insulin were significantly higher in $H$. pylori-infected group $(16.95 \pm 4.67 \mu \mathrm{U} / \mathrm{ml})$ compared to control group $(10.49 \pm 6.5 \mu \mathrm{U} / \mathrm{ml})$, $P=0.001$. The values of HOMA-IR index were significantly higher $(3.8 \pm 1.16)$ in $H$. pyloriinfected as compared to the control group (2.07 \pm 1.01 ), $P=0.001$ (Table 2).

To study the factors that might affect the results of the HOMA-IR model, we statically analyzed the correlations between different study variables and HOMA-IR values in both groups. The analysis showed that the level of fasting Insulin is directly proportional to $H$. pylori infection, where the higher levels of fasting Insulin were significantly correlated to positive $H$. pylori results of ELIZA, in contrast to the negative results with lower serum levels of Insulin (Table 3). 
Table (1): Demographic and Clinical characteristics of the study population:

\begin{tabular}{|c|c|c|c|c|}
\hline Variables & $\begin{array}{c}\text { H. Pylori } \\
\text { Negative } \\
(\mathrm{N}=28)\end{array}$ & $\begin{array}{l}\text { H. Pylori Positive } \\
(\mathrm{N}=34)\end{array}$ & P-value & Total \\
\hline \multirow{2}{*}{ Gender N. (\%) } & $10(35.7 \%)$ & $25(73.5 \%)$ & \multirow{2}{*}{$0.003 * *$} & $35(56 \%)$ \\
\hline & $18(64.3 \%)$ & $9(26.5 \%)$ & & $27(44 \%)$ \\
\hline Age (years) Mean \pm SD & $47.5 \pm 6.2$ & $47 \pm 4.82$ & 0.59 & \\
\hline BMI (\%) Mean \pm SD & $25.8 \pm 1.45$ & $27.24 \pm 1.17$ & $0.001 * *$ & \\
\hline \multicolumn{5}{|l|}{ Laboratory tests } \\
\hline CRP (mg/L) Mean +SD & $1.63 \pm 0.48$ & $1.33 \pm 0.48$ & $0.039 *$ & \\
\hline AST (U/L) Mean \pm SD & $30.07 \pm 8.3$ & $33.68 \pm 10.41$ & 0.099 & \\
\hline ALT (U/L) Mean \pm SD & $31.32 \pm 7.28$ & $27.18 \pm 12.33$ & 0.51 & \\
\hline Urea $(\mathrm{mg} / \mathrm{dL})$ Mean $\pm \mathrm{SD}$ & $25 \pm 4.6$ & $27.85 \pm 8.91$ & 0.072 & \\
\hline $\mathrm{sCr}(\mathrm{mg} / \mathrm{dl}) \mathrm{Mean} \pm \mathrm{SD}$ & $0.86 \pm 0.13$ & $0.9 \pm 0.22$ & 0.366 & \\
\hline \multicolumn{5}{|l|}{ Clinical symptoms } \\
\hline Abdominal pain N (\%) & $10(35.7 \%)$ & $12(35.3 \%)$ & \multirow{6}{*}{0.623} & $22(35 \%)$ \\
\hline Constipation N (\%) & $2(7.1 \%)$ & $7(20.6 \%)$ & & $9(15 \%)$ \\
\hline Diarrhea N (\%) & $2(7.1 \%)$ & $4(11.8 \%)$ & & $6(10 \%)$ \\
\hline Dyspepsia N (\%) & $6(21.4 \%)$ & $5(14.7 \%)$ & & $11(18 \%)$ \\
\hline Others N (\%) & $1(3.6 \%)$ & $1(2.9 \%)$ & & $2(3 \%)$ \\
\hline No symptoms N (\%) & $7(25 \%)$ & $5(14.7 \%)$ & & $12(19 \%)$ \\
\hline
\end{tabular}

*P-value $<0.05$, ** P-value $<0.01$.

$S D$ : Standard deviation; $s C r$ : serum creatinine; ALT: alanine transferase; AST: aspartate transaminase; CRP: $C$ reactive protein; BMI: Body Mass Index.

Table (2): Correlations between levels of fasting blood glucose, fasting insulin, and homeostasis model assessment of insulin resistance in the studied groups:

\begin{tabular}{cccc}
\hline Variables & $\begin{array}{c}\text { H. Pylori Negative } \\
(\mathbf{N}=\mathbf{2 8}) \text { Mean } \pm \text { SD }\end{array}$ & $\begin{array}{c}\text { H. Pylori Positive } \\
(\mathbf{N}=34) \text { Mean } \pm \text { SD }\end{array}$ & P-value \\
\hline $\begin{array}{c}\text { Fasting blood glucose } \\
(\mathbf{m g} / \mathbf{d l})\end{array}$ & $90.68 \pm 11.18$ & $92 \pm 6.67$ & 0.61 \\
\hline Fasting Insulin $(\boldsymbol{\mu U} / \mathrm{ml})$ & $10.49 \pm 6.5$ & $16.95 \pm 4.67$ & $0.001^{* *}$ \\
\hline HOMA-IR & $2.07 \pm 1.01$ & $3.8 \pm 1.16$ & $0.001^{* *}$ \\
\hline
\end{tabular}

** $P$-value $<0.01$.

SD: Standard deviation; HOMA-IR: Homeostasis Model Assessment of Insulin Resistance.

Table (3): Correlations between homeostasis model assessment of insulin resistance and other variables in the studied groups:

\begin{tabular}{lcccc}
\hline \multirow{2}{*}{ Variables } & \multicolumn{2}{c}{$\begin{array}{c}\text { Pylori Negative } \\
(\mathbf{N = 2 8})\end{array}$} & \multicolumn{2}{c}{$\begin{array}{c}\text { H. Pylori Positive } \\
(\mathbf{N}=\mathbf{3 4})\end{array}$} \\
\cline { 2 - 5 } & $\mathbf{r}$ & $\boldsymbol{P}$ value & $\mathbf{r}$ & P value \\
\hline Fasting blood glucose & 0.347 & 0.06 & 0.027 & 0.89 \\
\hline Fasting Insulin & 0.968 & $0.001^{* *}$ & 0.817 & $0.001^{* *}$ \\
\hline Urea & -0.444 & $0.01^{*}$ & 0.087 & 0.647 \\
\hline SCr & -0.529 & $0.003^{* *}$ & 0.166 & 0.318 \\
\hline BMI & 0.031 & 0.872 & 0.197 & 0.297 \\
\hline CRP & -0.738 & $0.001^{* *}$ & -0.179 & 0.344 \\
\hline
\end{tabular}

*P-value $<0.05, * * P$-value $<0.01$.

sCr: serum creatinine; CRP: C reactive protein; BMI: Body Mass Index.

\section{DISCUSSION}

Several studies showed a remarkable association between infection with $H$. pylori and IR [7, 19]. IR is associated with metabolic disturbances that cause the elevation of blood sugar in both obese and non-obese patients [20]. Several studies reported IR association with different inflammatory and cardiovascular diseases which causes excessive secretions of CRP [21-22] and other inflammatory interleukins such as IL-10 [23], IL-12 [24], and IL-29 [25], particularly in 
obese and diabetic patients [26]. However, the mechanism of IR in non-diabetic, non-obese patients is still unclear. Several studies used the algorithmic model of HOMA-IR to investigate the correlation between IR and different clinical complications [27] or other demographic-social features in a specific population [28]. In the current study, we tested the correlation between one of the most prevalent gastrointestinal issues, the $H$. pylori infection, and IR in non-diabetic, non-obese individuals in a single medical center (the outpatient virology clinics, Department of Gastroenterology and Hepatology, Sohag University Hospital, Egypt).

The results showed that $H$. pylori infection was more common among male patients. In agreement, a previous study showed that males are more susceptible to $\mathrm{H}$. pylori infection than women (OR: 1.16, 95\% CI: 1.11-1.22) which were associated with several inflammatory diseases such as ulcers and gastrointestinal tumors all over the world [29]. A previous study showed that most of the $H$. pylori seropositivity was among males (67.94\%) in Cameroon [30] while another meta-analysis study suggested that the male predominance in $H$. pylori infection might be due to poor hygiene and higher physical activity [29]. The hormonal profile of females was suggested to induce more protection against different types of gastric inflammations and infections because of the higher Th2 response and secreted antibodies [31].

The results of the current study showed that $H$. pylori infection had significantly higher CRP levels. Similarly, several studies showed that the serum levels of CRP in infected patients were higher than in healthy individuals [32-34] which indicated that $\mathrm{H}$. pylori infection stimulates the production of different inflammatory cytokines such as IL-1 $\beta$, IL-6, TNF- $\alpha$ [35]. Furthermore, the current study reported a slight increase in the blood levels of AST, Urea, and $\mathrm{sCr}$, which is in agreement with the findings of several previous studies [36-37].

The main target of the current study was to evaluate the association between $H$. pylori infection and IR in non-diabetic, non-obese patients from Sohag, Egypt. As shown in the results section, the levels of the fasting insulin in the $H$. pylori-infected group were higher than the control group, despite normal serum glucose level which indicated a higher level of insulin resistance. Furthermore, the results showed higher values for HOMA-IR with $H$. pylori infection compared to the control. In disagreement with our findings, a recent study was conducted on $H$. pylori-infected patients from Cairo, Egypt, showed insignificant difference between infected and healthy individuals in the respect of HOMA-IR, However, the nonalcoholic fatty liver disease (NAFLD) fibrosis scores were significant among H. pylori infection cases [38]. Similar to our results, a study from Tanta, Egypt, showed a significant increase in the levels of fasting insulin $(17.2 \pm 2.74 \mathrm{IU} / \mathrm{m})$ and HOMA-IR scores (3.66 \pm 1.26$)$ in the $H$. pylori infection patients who were either non-obese or non-diabetic individuals [39]. Another study from Taiwan showed that HOMA-IR score > 2.5 and higher levels of TNFa were associated with $H$. pylori infection in patients with ideal BMI and normal fasting blood sugar levels, but with higher leptin values which indicated an insulin resistance and metabolic syndrome [7]. Another study from Iran compared the levels of insulin resistance and HOMA-IR in both diabetic and non-diabetic patients and reported that in both categories the infection with $H$. pylori had a higher value of IR and HOMA-IR scores $>3$ [40]. All of these studies demonstrated the robust direct relationship between $\mathrm{H}$. pylori infection and IR which might explain all the observed inflammatory activities reported in the non-obese non-diabetic patients.

\section{CONCLUSIONS:}

The current study demonstrated the positive relationship of $H$. pylori infection with the abnormal levels of serum insulin in non-diabetic, non-obese patients from Sohag, Egypt. HOMAIR index is a reliable indicator of IR accompanied with $H$. pylori infection which might a significant indicator for other more complications and severe medical issues. Further longitudinal cohort studies are required to investigate the usage of HOMA-IR in the prediction of different IR and $H$. pyloriassociated diseases in different medical centers from Egypt.

Funding: None. Author funded.

Conflict of interest: None.

\section{Ethical Consideration:}

The current study had an approval from the Ethics Committee of the Faculty of Medicine, 
Sohag University, Egypt, according to the World Medical Association (WMA) Declaration of Helsinki https://www.wma.net/policiespost/wma-declaration-of-helsinki-ethicalprinciples-for-medical-research-involvinghuman-subjects/. All informed consents were approved and signed by all participants.

\section{REFERENCES}

1. Burucoa C, Axon A. Epidemiology of Helicobacter pylori infection. Helicobacter 2017;22 (1) https://doi.org/10.1111/hel.12403

2. Warren JR, Marshall B. Unidentified curved bacilli on gastric epithelium in active chronic gastritis. Lancet 1983;1(8336):1273-1275.

3. Pereira MI, Medeiros JA. Role of Helicobacter pylori in gastric mucosa-associated lymphoid tissue lymphomas. World J Gastroenterol. 2014;20(3):684-698. https://doi.org/10.3748/wjg.v20.i3.684.

4. Parsonnet J. Helicobacter pylori and gastric cancer. Gastroenterol Clin North Am 1993; 22:89-104.

5. Testerman TL, Morris J. Beyond the stomach: an updated view of Helicobacter pylori pathogenesis, diagnosis, and treatment. World $J$ Gastroenterol 2014;20(36):12781-12808 https://doi.org/10.3748/wjg.v20.i36.12781.

6. Franceschi F, Annalisa T, Teresa DR, Giovanna D, Ianiro G, Franco S et al. Role of Helicobacter pylori infection on nutrition and metabolism. World J Gastroenterol. 2014;20(36):1280912817. https://doi.org/10.3748/wjg.v20.i36.12809.

7. Chen LW, Chien CY, Yang KJ, Kuo SF, Chen $\mathrm{CH}$, Chien RN. Helicobacter pylori Infection Increases Insulin Resistance and Metabolic Syndrome in Residents Younger than 50 Years Old: A Community-Based Study. PLoS One 2015;10(5):e0128671 https://doi.org/10.1371/journal.pone.0128671.

8. Bravo D, Hoare A, Soto C, Valenzuela MA, Quest AF. Helicobacter pylori in human health and disease: Mechanisms for local gastric and systemic effects. World $J$ Gastroenterol 2018;24(28):3071-3089

https://doi.org/10.3748/wjg.v24.i28.3071.

9. Aydemir S, Bayraktaroglu T, Sert M, Sokmen C, Atmaca H, Mungan $G$ et al. The effect of Helicobacter pylori on insulin resistance. Dig Dis $\quad$ Sci 2005; 50:2090-2093 https://doi.org/10.1007/s10620-005-3012-z.

10. Petersen MC, Shulman GI. Mechanisms of Insulin Action and Insulin Resistance. Physiol Rev 2018;98(4):2133-2223 https://doi.org/10.1152/physrev.00063.2017.
11. Matthaei S, Stumvoll M, Kellerer M, Haring HU. Pathophysiology and pharmacological treatment of insulin resistance. Endocr Rev 2000 ; 21:585-618 https://doi.org/10.1210/edrv.21.6.0413.

12. Ormazabal V, Nair S, Elfeky O, Aguayo C, Salomon C, Zuñiga FA. Association between insulin resistance and the development of cardiovascular disease. Cardiovasc Diabetol. 2018;17(1):122 https://doi.org/10.1186/s12933018-0762-4.

13. Ellulu MS, Patimah I, Khaza'ai H, Rahmat A, Abed Y. Obesity and inflammation: the linking mechanism and the complications. Arch Med Sci. 2017;13(4):851-863 https://doi.org/10.5114/aoms.2016.58928.

14. Fahed M, Abou Jaoudeh MG, Merhi S, Mosleh JMB, Ghadieh R, Al Hayek S et al. Evaluation of risk factors for insulin resistance: a cross sectional study among employees at a private university in Lebanon. BMC Endocr Disord. 2020;20(1):85. https://doi.org/10.1186/s12902020-00558-9

15. He C, Yang Z, Lu NH. Helicobacter pylori infection and diabetes: is it a myth or fact?. World J Gastroenterol 2014;20(16):4607-4617 https://doi.org/10.3748/wjg.v20.i16.4607.

16. Matthews DR, Hosker JP, Rudenski AS, Naylor BA, Treacher DF, Turner RC. Homeostasis model assessment: insulin resistance and betacell function from fasting plasma glucose and insulin concentrations in man. Diabetologia 1985;28(7):412-419 https://doi.org/10.1007/BF00280883.

17. Gutch M, Kumar S, Razi SM, Gupta KK, Gupta A. Assessment of insulin sensitivity/resistance. Indian J Endocrinol Metab 2015;19(1):160-164 https://doi.org/10.4103/2230-8210.146874.

18. Majid H, Masood Q, Khan AH. Homeostatic Model Assessment for Insulin Resistance (HOMA-IR): A Better Marker for Evaluating Insulin Resistance Than Fasting Insulin in Women with Polycystic Ovarian Syndrome. J Coll Physicians Surg Pak 2017; 27(3):123-126.

19. Polyzos SA, Kountouras J, Zavos C, Deretzi G. The association between Helicobacter pylori infection and insulin resistance: a systematic review. Helicobacter 2011;16(2):79-88 https://doi.org/10.1111/j.15235378.2011.00822.x.

20. Roberts CK, Hevener AL, Barnard RJ. Metabolic syndrome and insulin resistance: underlying causes and modification by exercise training. Compr Physiol. 2013;3(1):1-58 https://doi.org/10.1002/cphy.c110062.

21. Festa A, Hanley AJ, Tracy RP, D’Agostino R Jr, Haffner SM. Inflammation in the prediabetic state is related to increased insulin resistance rather than decreased insulin secretion. 
Circulation 2003; 108: 1822-1830 https://doi.org/10.1161/01.CIR.0000091339.701 20.53.

22. Festa A, D’Agostino R Jr, Tracy RP, Haffner SM. C-reactive protein is more strongly related to post-glucose load glucose than to fasting glucose in non-diabetic subjects: the Insulin Resistance Atherosclerosis Study. Diabet Med 2002; 19:

939-943

https://doi.org/10.1046/j.14645491.2002.00824.x.

23. Hong EG, Ko HJ, Cho YR, Kim HJ, Ma Z, Yu TY et al. Interleukin-10 prevents diet-induced insulin resistance by attenuating macrophage and cytokine response in skeletal muscle. Diabetes 2009;58(11):2525-2535 https://doi.org/10.2337/db08-1261.

24. Memon AA, Sundquist J, Wang X, Palmér K, Sundquist K, Bennet L. The association between cytokines and insulin sensitivity in Iraqi immigrants and native Swedes. BMJ Open 2013;3(11):e003473 https://doi.org/10.1136/bmjopen-2013-003473.

25. Lin TY, Chiu CJ, Kuan CH, Chen FH, Shen YC, $\mathrm{Wu} \mathrm{CH}$ et al. IL-29 promoted obesity-induced inflammation and insulin resistance. Cell Mol Immunol 2020, 17, 369-379 https://doi.org/10.1038/s41423-019-0262-9.

26. Wellen KE, Hotamisligil GS. Obesity-induced inflammatory changes in adipose tissue. J Clin Invest 2003; 112: 1785-1788 https://doi.org/10.1172/JCI20514.

27. Mossmann M, Wainstein MV, Gonçalves SC, Wainstein RV, Gravina GL, Sangalli M, et al. HOMA-IR is associated with significant angiographic coronary artery disease in nondiabetic, non-obese individuals: a cross-sectional study. Diabetol Metab Syndr 2015; 7:100 https://doi.org/10.1186/s13098-015-0085-5.

28. Fernström M, Fernberg U, Hurtig-Wennlöf A. Insulin resistance (HOMA-IR) and body fat (\%) are associated to low intake of fruit and vegetables in Swedish, young adults: the crosssectional lifestyle, biomarkers and atherosclerosis study. BMC Nutr 2019; 5:15 https://doi.org/10.1186/s40795-019-0279-6.

29. de Martel C, Parsonnet J. Helicobacter pylori infection and gender: a meta-analysis of population-based prevalence surveys. Dig Dis Sci. 2006;51: 2292-2301 https://doi.org/10.1007/s10620-006-9210-5.

30. Kouitcheu Mabeku, L.B., Noundjeu Ngamga, M.L., Leundji, H. Potential risk factors and prevalence of Helicobacter pylori infection among adult patients with dyspepsia symptoms in Cameroon. BMC Infect Dis 2018; 18: 278 https://doi.org/10.1186/s12879-018-3146-1.
31. Taneja V. Sex Hormones Determine Immune Response. Front Immunol. 2018; 9:1931 https://doi.org/10.3389/fimmu.2018.01931.

32. Jafarzadeh A, Hassanshahi GH, Nemati M. Serum levels of high-sensitivity C-reactive protein (hs-CRP) in Helicobacter pylori-infected peptic ulcer patients and its association with bacterial CagA virulence factor. Dig Dis Sci 2009;

54(12):2612-2616 https://doi.org/10.1007/s10620-008-0686-z.

33. Ishida Y, Suzuki K, Taki K, Niwa T, Kurotsuchi $\mathrm{S}$, Ando $\mathrm{H}$, et al. Significant association between Helicobacter pylori infection and serum Creactive protein. Int J Med Sci. 2008;5(4):224229 https://doi.org/10.7150/ijms.5.224.

34. Altun E, Yildiz A, Cevik C, Turan G. The role of high sensitive C-reactive protein and histopathological evaluation in chronic gastritis patients with or without Helicobacter pylori infection. Acta Cir Bras 2019;34(3):e201900310 https://doi.org/10.1590/s0102865020190030000010.

35. Sheldon J, Riches P, Gooding R, Soni N, Hobbs JR. C-reactive protein and its cytokine mediators in intensive-care patients. Clin Chem 1993;39(1):147-150.

36. Tsukada K, Miyazaki T, Katoh H, Yoshikawa M, Masuda N, Ojima $\mathrm{H}$, et al. Helicobacter pylori infection in hemodialysis patients. Hepatogastroenterology. 2003; 50(54):22552258.

37. Zhao MM, Krebs J, Cao X, Cui J, Chen DN, Li $\mathrm{Y}$, et al. Helicobacter pylori infection as a risk factor for serum bilirubin change and less favourable lipid profiles: a hospital-based health examination survey. BMC Infect Dis 2019;19(1):157 https://doi.org/10.1186/s12879$\underline{019-3787-8}$.

38. Allam AS, Bawady S, Abdelhalim ASA, ElNakeep S. Effect of Helicobacter pylori on insulin resistance in nonobese, nondiabetic, and normolipidemic Egyptian patients. Egypt Liver J 2018; $8(1): 23-28$ https://doi.org/10.1097/01.ELX.0000530582.250 24.9fs.

39. Esheba NE, Nagy HM. Helicobacter pylori infection: a risk factor for insulin resistance in nonobese nondiabetic individuals. Tanta Med J 2016; 44 (2):76-80 https://doi.org/10.4103/11101415.189344.

40. Vafaeimanesh J, Parham M, Seyyedmajidi M, Bagherzadeh M. Helicobacter pylori infection and insulin resistance in diabetic and nondiabetic population. Sci World J 2014; 2014:391250 https://doi.org/10.1155/2014/391250. 